\title{
Evaluation of clinical breast examination and breast ultrasonography among pregnant women in Abakaliki, Nigeria
}

This article was published in the following Dove Press journal:

OncoTargets and Therapy

13 May 2015

Number of times this article has been viewed

\author{
Paul Olisaemeka Ezeonu' \\ Leonard Ogbonna Ajah' \\ Robinson Chukwudi Onoh' \\ Lucky Osaheni Lawani' \\ Vincent Chidi Enemuo ${ }^{2}$ \\ Uzoma MaryRose Agwu' \\ 'Department of Obstetrics and \\ Gynecology, ${ }^{2}$ Department of Surgery, \\ Federal Teaching Hospital, Abakaliki, \\ Ebonyi State, Nigeria
}

Background: Breast cancer in pregnancy accounts for $2 \%-3 \%$ of all breast cancers. The increased vascularity and lymphatic drainage from the breast during pregnancy potentiate the metastatic spread of the cancer to the regional lymph nodes. However, the increased breast density in pregnancy makes it difficult to detect breast lesions early.

Aim: To evaluate and compare the detection rate of breast lesions using clinical breast examination (CBE) and breast ultrasonography among pregnant women.

Methodology: A cross-sectional comparative study involving antenatal clinic attendees at the Federal Teaching Hospital, Abakaliki, was conducted between March 3, 2014, and December 31, 2014. CBE and breast ultrasonography were done in the participants at booking and repeated at 6 weeks postpartum. Fine-needle aspiration cytology and histology were done in women with suspicious breast lesions on CBE or breast ultrasonography or both. Data analysis was both descriptive and inferential at the 95\% confidence level using the Statistical Package for the Social Sciences (SPSS) software version 17.0. Test of significance was done using chi-square test. A $P$-value of less than or equal to 0.05 was considered statistically significant.

Results: A total of 320 pregnant women participated in the study. Of these, 267 (83.4\%) were aware of breast cancer. Although more lesions were detected with breast ultrasonography than by $\mathrm{CBE}$, there was no statistically significant difference between them ( 25 versus $17 ; P=0.26$ ). The histology of the lesions revealed 21 benign lesions and 4 normal breast tissues. The sensitivity of breast ultrasonography was $95.2 \%$, while that of CBE was $66.7 \%$. The specificity, positive predictive value, and negative predictive value were similar between $\mathrm{CBE}$ and breast ultrasonography.

Conclusion: The detection rates of breast lesions by both CBE and breast ultrasonography were equivalent during pregnancy and 6 weeks postpartum, making $\mathrm{CBE}$ a convenient and very cost-effective method of detecting breast lesions in the low-risk population. However, both CBE and breast ultrasonography should be done in women with high risk of breast malignancy.

Keywords: clinical breast examination, breast ultrasonography, pregnant women, breast lesion, Nigeria

\section{Introduction}

The current incidence of breast cancer in pregnancy is approximately between 1.3 and 2.4 per 10,000 live births, which equates to $2 \%-3 \%$ of total breast cancers. The incidence is expected to increase as more women delay childbearing for socioeconomic reasons. ${ }^{1}$ The increased vascularity and lymphatic drainage from the breast during pregnancy potentiate the metastatic spread of the cancer to the regional lymph nodes. Therefore, early detection of breast cancer is the best method of reducing morbidity and mortality from it. ${ }^{3}$
Correspondence: Leonard Ogbonna Ajah Department of Obstetrics and Gynecology, Federal Teaching Hospital, P.M.B I02, Abakaliki, Nigeria

Tel +2348033920789

Email leookpanku@yahoo.com 
Mammography is less sensitive and specific among premenopausal women, especially during pregnancy. This is due to the increase in breast density and intense breast cellular proliferative activity in pregnancy. ${ }^{4,5}$ Even though the radiation risk to the fetus is insignificant, with the fetal dose estimated to be $0.05 \mu \mathrm{Gy},{ }^{4}$ the radiation dose to the breast will, however, be raised, and the effects of this on this radiosensitive population cannot be ignored. ${ }^{4}$ Besides, benign microcalcifications are common in pregnancy, and may resemble breast malignancy. ${ }^{6,7}$

Ultrasonography can be used to differentiate between cysts and solid tumors and can help in visualization during fine-needle aspiration procedures of the breast that can aid in diagnosis. It is usually used in conjunction with mammography, especially when the mammography findings are equivocal. Several studies support the use of ultrasonography for breast cancer screening as an adjunct to mammography for high-risk women or women with dense breasts. ${ }^{8}$ However, due to the fear of teratogenicity associated with mammography during pregnancy and the low detection rate of mammography on the dense breasts of pregnant women, ultrasound breast screening may be preferable during pregnancy. One study showed that sensitivity was approximately $83.3 \%$ and specificity was $65.5 \%$ for breast ultrasonography. ${ }^{9}$ A previous comparative study on the sensitivity of breast sonography, mammography, and clinical breast examination (CBE) showed that breast sonography had the highest sensitivity. ${ }^{10}$

Nigeria, like other sub-Saharan African countries, does not have organized breast cancer screening programs. What is obtainable in this region is opportunistic screening. There is a preponderance of poor health-seeking behavior especially in Ebonyi State. This is mainly due to poverty, ignorance, and lack of functional health facilities. The management of breast cancer in pregnancy is difficult globally. But it is more difficult in our region, where most of the women with breast malignancy present late. ${ }^{11}$ The cultural affinity for high parity and negation to abortion in our environment may make many pregnant women with breast malignancy reject chemoradiation, irrespective of the gestational age, if they know that it may terminate their pregnancy. It therefore becomes important that breast cancer screening is encouraged in our environment. Even though routine CBE is carried out on every booking antenatal clinic attendee at the study center, it is associated with low sensitivity and specificity. ${ }^{12,13}$ Breast sonography among booking antenatal women may be feasible in view of its ready availability in our environment as well as its high sensitivity and specificity. The findings from this study may help in policy formulation on the best ways of breast cancer screening in our environment. There was paucity of studies on this subject matter in this environment. It was in view of the aforementioned reasons that this study was embarked upon. Our study was aimed at evaluating and comparing the detection rates of breast lesions using $\mathrm{CBE}$ and breast ultrasonography among the study participants.

\section{Methodology}

Abakaliki is the capital of Ebonyi State with an estimated population of 4.3 million according to the 2006 national census. It occupies a land mass of 5,935 square kilometers. About $75 \%$ of the population of Ebonyi State dwell in the rural areas, with farming as the major occupation. ${ }^{14}$ This was a crosssectional comparative study in which consenting booking antenatal clinic attendees were recruited for the study at the Antenatal Clinic of Federal Teaching Hospital, Abakaliki (FETHA), between March 3, 2014, and December 31, 2014. At FETHA and many other hospitals in Nigeria, CBE is routinely done for booking antenatal clinic attendees. A proforma was used to collate information on the sociodemographic characteristics of the women, their gestational age, knowledge of breast cancer and its risk factors, CBE findings, breast sonographic findings, and the histology reports of the biopsy specimens. The women had breast ultrasonography after the CBE. The Voluson 730 Pro V, a three-dimensional ultrasound produced by General Electric Medical Systems, Kretzetechnik GmbH and Co OHG, Tiefenbach, Austria, was used for the breast sonography. The power Doppler was used to check the vascularity of the breast lesions. The breast ultrasonography was done by two radiologists. There was a single blinding in which the trained research assistant doing the CBE did not know the breast sonographer's findings and vice versa. The CBE and breast ultrasonography were done for the participants at booking and repeated at 6 weeks postpartum. The main outcome measure consisted of the histology of the detected breast lesions from ultrasonography and/or CBE. Phone calls and even home visitation (for women who lost their phones) were made with the aim of reminding the women to honor their 6 weeks postpartum appointment. Fine-needle aspiration cytology (FNAC) was done on the women with suspicious breast lesions on CBE or breast ultrasonography or both and the histology of the specimen was done. The gold standard consisted of the histology results and 6 weeks postpartum repeat $\mathrm{CBE}$ and breast ultrasonography.

Using a breast cancer prevalent rate of $25.7 \%,{ }^{15}$ the minimum sample size for the study was calculated based on 
the formula for estimating sample size for prevalent studies described by Daniel: ${ }^{16}$

$$
n=\frac{Z^{2} P(1-P)}{d^{2}}
$$

where $n$ is the sample size, $Z$ is the $z$ statistics for $95 \%$ level of confidence, $P$ is the expected prevalence or proportion, and $d$ is the precision. With $Z=1.96, P=0.257$, and $d=0.05$, and adding an assumed attrition rate of $10 \%$, the calculated sample size was 322 .

Every consenting booking antenatal clinic attendee who participated in both CBE and breast ultrasonography and came for the 6 weeks follow-up was included in the study. The participants with suspicious breast lesions who had their breast biopsy and histology reports collated were also included. However, the exclusion criteria consisted of the booking antenatal clinic attendees who declined consent to participate in the study despite adequate counseling or who did not participate in both CBE and breast ultrasonography or who did not come for the 6 weeks repeat CBE and breast sonography. Similarly, participants with suspicious breast lesions who declined biopsy and histology of the specimens were also excluded. The ethical clearance for this study was obtained from the Ethics Committee of the Federal Teaching Hospital, Abakaliki.

\section{Data analysis}

Data analysis was both descriptive and inferential at the $95 \%$ confidence level using the Statistical Package for the Social Sciences (SPSS) software version 17.0 (SPSS Inc., Chicago, IL, USA). Test of significance was done with chi-square test. A $P$-value of 0.05 or less was considered statistically significant.

\section{Results}

A total of 320 booking antenatal women who met the inclusion criteria participated in the study. The mean booking gestational age was $24 \pm 5$ weeks. Table 1 shows the sociodemographic characteristics of the participants. Majority of the participants were between 25 and 34 years, urban dwellers, Ibos, civil servants, and had tertiary education and high parity. The awareness of and risk factors for breast malignancy are presented in Table 2. A total of 267 (83.4\%) of the participants were aware of breast cancer. Most (69.1\%) of the participants had their first childbirth at $\leq 24$ years. More so, 18 (5.6\%), 29 (9.1\%), 7 (2.2\%), and 60 (18.8\%) of the participants had a family history of breast, ovarian, and colorectal cancers, a history of use of hormonal contraceptives, tobacco, and alcohol, respectively.
Table I Sociodemographic characteristics of the booking antenatal women

\begin{tabular}{|c|c|c|}
\hline $\begin{array}{l}\text { Sociodemographic } \\
\text { characteristics }\end{array}$ & $\begin{array}{l}\text { Frequency } \\
(\mathrm{N}=320)\end{array}$ & $\%$ \\
\hline \multicolumn{3}{|l|}{ Age (years) } \\
\hline $20-24$ & 63 & 19.7 \\
\hline $25-29$ & 158 & 49.4 \\
\hline $30-34$ & 80 & 25.0 \\
\hline $35-39$ & 19 & 5.9 \\
\hline \multicolumn{3}{|l|}{ Area } \\
\hline Rural & 100 & 31.3 \\
\hline Urban & 220 & 68.8 \\
\hline \multicolumn{3}{|c|}{ Educational qualification } \\
\hline Primary & 18 & 5.6 \\
\hline Secondary & $|4|$ & 44.1 \\
\hline Tertiary & 161 & 50.3 \\
\hline \multicolumn{3}{|l|}{ Tribe } \\
\hline lbo & 285 & 80.1 \\
\hline Yoruba & 5 & 1.6 \\
\hline Hausa & 3 & 0.9 \\
\hline Others $^{\mathrm{a}}$ & 27 & 8.4 \\
\hline \multicolumn{3}{|l|}{ Occupation } \\
\hline Unemployed & 100 & 31.3 \\
\hline Teaching & 20 & 6.3 \\
\hline Civil service & $12 \mid$ & 37.8 \\
\hline Trading & 38 & 11.9 \\
\hline Artisans & 20 & 6.3 \\
\hline Professional ${ }^{b}$ & 21 & 6.6 \\
\hline \multicolumn{3}{|l|}{ Parity } \\
\hline 0 & 56 & 17.5 \\
\hline I & 60 & 18.8 \\
\hline $2-4$ & 135 & 42.2 \\
\hline$>4$ & 69 & 21.6 \\
\hline
\end{tabular}

Table 3 compares the CBE and ultrasound findings. Even though there were more findings from breast ultrasonography than from CBE, there was no statistically significant difference between them ( 25 versus $17 ; P$-value $=0.26$ ). Table 4 shows the dimensions of the breast lesions on $\mathrm{CBE}$ and ultrasonography. Breast ultrasound scan detected smaller lesions more than the CBE did. Also, the solid lesions were detected more than the cystic lesions. The histologic diagnosis of the breast lesions and its comparison with $\mathrm{CBE}$ and ultrasound findings are presented in Tables 5 and 6 . Fibroadenoma accounted for the majority (28\%) of the breast lesions, followed by lactating adenoma. The others were fibrocystic disease (16\%), lipoma (8\%), breast abscess (8\%), mastitis (4\%), and normal breast tissue (16\%) (Table 5). Even though the sensitivity of breast ultrasonography (95.2\%) was more than that of $\mathrm{CBE}(66.7 \%)$, there was no statistically significant difference between them $(P>0.05)$. However, the specificity, positive predictive value (PPV), 
Table 2 The awareness of and risk factors for breast malignancy

\begin{tabular}{lll}
\hline $\begin{array}{l}\text { Awareness and } \\
\text { risk factors }\end{array}$ & $\begin{array}{l}\text { Frequency } \\
(\mathbf{N}=\mathbf{3 2 0})\end{array}$ & $\%$ \\
\hline $\begin{array}{l}\text { Awareness of breast cancer } \\
\text { Yes }\end{array}$ & 267 & 83.4 \\
No & 53 & 16.6 \\
Age at first childbirth & 100 & \\
$<20$ & 121 & 31.3 \\
$20-24$ & 58 & 37.8 \\
$25-29$ & 41 & 18.1 \\
$30-34$ & 29 & 12.8 \\
History of prior use of hormonal contraceptives & \\
Yes & 291 & 9.1 \\
No & 18 & 90.9 \\
Family history of breast, colorectal, and ovarian cancers & \\
Yes & 302 & 5.6 \\
No & & 94.4 \\
Use of tobacco & 7 & \\
Yes & 313 & 2.2 \\
No & & 97.8 \\
Use of alcohol & 60 & \\
Yes & 260 & 18.8 \\
No & & 81.3 \\
\hline
\end{tabular}

and negative predictive value (NPV) were similar between $\mathrm{CBE}$ and breast ultrasonography (Table 6).

\section{Discussion}

The principal findings from this study showed that 267 $(83.4 \%)$ of the participants were aware of breast cancer. Even though there were more findings from breast ultrasonography than from CBE, there was no statistically significant difference between them ( 25 versus $17 ; P$-value $=0.26$ ). Breast ultrasound scan detected smaller and cystic lesions more than did the CBE. The histology of the lesions showed $72 \%$ benign breast lesions, $12 \%$ inflammatory breast lesions, and $16 \%$ normal breast tissue. Even though the sensitivity of breast ultrasonography (95.2\%) was more than that of $\mathrm{CBE}$ $(66.7 \%)$, there was no statistically significant difference between them $(P>0.05)$. The specificity, PPV, and NPV were similar between $\mathrm{CBE}$ and breast ultrasonography.

The $83.4 \%$ of the antenatal clinic attendees who were aware of breast cancer in this study is similar to the $80 \%$ reported in Pakistan. ${ }^{17}$ The high breast cancer awareness among the study participants may have been due to the high educational status of the majority of them. Also, this could be adduced to the

Table 3 Comparison of CBE and ultrasound findings

\begin{tabular}{llll}
\hline Findings & $\mathbf{N}=\mathbf{3 2 0}$ & & \\
\cline { 2 - 4 } & $\mathbf{C B E}$ & Ultrasound & $\boldsymbol{P}$-value \\
\hline Cystic lesions & 7 & 12 & 0.26 \\
Solid lesions & 10 & 13 & \\
Normal & 303 & 295 & \\
\hline
\end{tabular}

Abbreviation: $\mathrm{CBE}$, clinical breast examination.
Table 4 The dimensions of the lesions

\begin{tabular}{|c|c|c|c|c|c|c|}
\hline \multirow[t]{2}{*}{ Tumors } & \multicolumn{3}{|l|}{ CBE } & \multicolumn{3}{|c|}{ Ultrasound } \\
\hline & $<\mathbf{I} \mathbf{c m}$ & $\mathrm{I}-2 \mathrm{~cm}$ & $3-4 \mathrm{~cm}$ & $<\mathbf{l} \mathbf{c m}$ & I-2 cm & $3-4 \mathrm{~cm}$ \\
\hline Cystic lesions & I & 2 & 4 & 5 & 3 & 4 \\
\hline Solid lesions & 3 & 4 & 3 & 4 & 6 & 3 \\
\hline
\end{tabular}

Abbreviation: $\mathrm{CBE}$, clinical breast examination.

majority of the study participants being urban dwellers. The absence of malignant tumors from this study may have been due to the young age of the participants ( $<40$ years), younger age at first childbirth, and high parity. It could also be due to the reduced number of participants with a family history of breast, colorectal, and ovarian malignancy and low prevalence of hormonal contraception and tobacco use among the participants. These protective factors have been previously reported by Okobia and Bunker. ${ }^{18}$ The sensitivity of $95.2 \%$ recorded from ultrasonography in this study is similar to $90.4 \%$ and $100 \%$ reported in Taiwan and USA, respectively. ${ }^{10,19}$ However, it is slightly higher than the $83.3 \%$ reported from Singapore. ${ }^{12}$ Also the specificity and NPV of breast ultrasonography recorded in this study are similar to those reported in USA. ${ }^{19}$ However, the PPV of $19 \%$ reported by Robbins et $\mathrm{al}^{19}$ is remarkably less than the $82.4 \%$ reported in this study.

The $66.7 \%$ sensitivity of CBE in this study is similar to the $69 \%$ reported from Iran, ${ }^{20}$ but higher than the $33 \%$ reported from Taiwan. ${ }^{13}$ However, the specificity, PPV, and NPV of CBE from this study are higher than those reported from Iran. ${ }^{20}$ The absence of statistically significant difference between $\mathrm{CBE}$ and breast ultrasonography in this study implies that CBE is a very cost-effective method of detecting breast lesions. Therefore, in a low-resource setting like ours, CBE should be advocated for the low-risk population. However, both CBE and breast ultrasonography should be done for women with high risk of breast malignancy. Breast ultrasonography can also be used as an adjunct to $\mathrm{CBE}$ because it can characterize the lesion detected through CBE.

Table 5 Histologic diagnosis of the lesions ${ }^{\mathrm{a}}$ and its comparison with $\mathrm{CBE}$ and ultrasound findings

\begin{tabular}{lll}
\hline Tumor & Frequency & $\%$ \\
\hline Fibroadenoma & 7 & 28 \\
Lactating adenoma & 5 & 20 \\
Fibrocystic disease & 4 & 16 \\
Lipoma & 2 & 8 \\
Breast abscess & 2 & 8 \\
Mastitis & 1 & 4 \\
Normal & 4 & 16 \\
Total & 25 & 100 \\
\hline
\end{tabular}

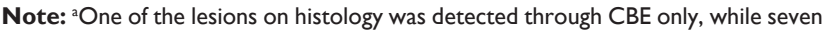
were detected through ultrasound only.

Abbreviation: $\mathrm{CBE}$, clinical breast examination. 
Table 6 Comparison of breast lesion detection with CBE and ultrasound

\begin{tabular}{llllll}
\hline Procedure & Sensitivity (\%) & Specificity (\%) & PPV (\%) & NPV (\%) & P-value \\
\hline CBE $^{\mathrm{a}}$ & 66.7 & 99.0 & 82.4 & 97.7 & $>0.05$ \\
Ultrasound $^{\mathrm{b}}$ & 95.2 & 98.7 & 80 & 99.7 & \\
\hline
\end{tabular}

Notes: a Lesions, 14, normal breast tissue 3; blesions, 20, normal breast tissue 5.

Abbreviations: CBE, clinical breast examination; PPV, positive predictive value; NPV, negative predictive value.

Fibroadenoma and lactating adenoma were the commonest benign breast tumors in this study, which is similar to the results previously report from Spain. ${ }^{21}$ However, inflammatory breast lesions (breast abscess and mastitis) accounted for $20 \%$ of the breast lesions in this study, which is much lower than the $70 \%$ reported from Spain. ${ }^{21}$

This study was strengthened by the histology of the suspicious lesions and the repeat $\mathrm{CBE}$ and breast ultrasonography at 6 weeks follow-up in order to enhance the validity of the findings. However, it was weakened by the hospitalbased design, which may not be a true reflection of what is happening in the society.

In conclusion, the detection rates of breast lesions by both CBE and breast ultrasonography were equivalent during pregnancy and 6 weeks postpartum, making CBE a convenient and very cost-effective method of detecting breast lesions in our environment. However, both $\mathrm{CBE}$ and breast ultrasonography should be applied for women with high risk of breast malignancy. A community-based study on this subject matter is advocated especially in our environment that lacks organized breast cancer screening programs.

\section{Disclosure}

The authors report no conflicts of interest in this work.

\section{References}

1. Andersson TM, Johansson AL, Hsieh CC, Cnattingius S, Lambe M. Increasing incidence of pregnancy-associated breast cancer in Sweden. Obstet Gynecol. 2009;114(3):568-572. doi:10.1097/AOG.0b013e3181b19154.

2. Garba ES, Uyanne P, Oguntayo AO, Lafia S, Udezue NO. Breast cancer in pregnancy: management approach. Nig J Surg Res. 2001;3:111-117.

3. Humphrey LL, Helfand M, Chan BK, Woolf SH. Breast cancer screening: a summary of the evidence for the U.S. Preventive Services Task Force. Ann Intern Med. 2002;137:347-360.

4. National Health Service (NHS). In: Hubbard Anne, editor. Screening for Breast Cancer in High Risk Women during Pregnancy and Lactation. NHSBSP Occasional Report 12/02. Sheffield, UK: NHS Cancer Screening Programmes; 2012.

OncoTargets and Therapy

\section{Publish your work in this journal}

OncoTargets and Therapy is an international, peer-reviewed, open access journal focusing on the pathological basis of all cancers, potential targets for therapy and treatment protocols employed to improve the management of cancer patients. The journal also focuses on the impact of management programs and new therapeutic agents and protocols on
5. Buist DS, Porter PL, Lehman C, Taplin SH, White E. Factors contributing to mammography failure in women aged $40-49$ years. J Natl Cancer Inst. 2004;96:1432-1440.

6. Stucker DT, Ikeda DM, Hartman AR, et al. New bilateral microcalcifications at mammography in a postlactational woman: case report. Radiology. 2000;217:247-250.

7. Giron GL, Boolbol SK, Gross J, Cohen JM, Feldman S. Postlactational microcalcifications. Breast J. 2004;10:247-252.

8. National Cancer Institute. Improving methods for breast cancer detection and diagnosis. Available from: http://www.cancer.gov/cancertopics/ factsheet/Detection/breast-cancer. Accessed September 16, 2008.

9. Pisano ED, Gatsonis C, Hendrick E, et al. Diagnostic performance of digital vs film mammography for breast cancer. $N$ Engl J Med. 2005; 353:1773-1783.

10. Sim L, Hendriks J, Fook-Chong S. Breast ultrasound in women with familial risk of breast cancer. Ann Acad Med Singapore. 2004;33(5): 600-606.

11. Kene TS, Odigie VI, Yusufu LM, Yusuf BO, Shehu SM, Kase JT. Pattern of presentation and survival of breast cancer in a teaching hospital in north Western Nigeria. Oman Med J. 2010;25(2):104-107.

12. Hou MF, Chuang HY, Ou-Yang F, et al. Comparison of breast mammography, sonography and physical examination for screening women at high risk of breast cancer in Taiwan. Ultrasound Med Biol. 2002;28(4): 415-420.

13. Bancej C, Decker K, Chiarelli A, Harrison M, Turner D, Brisson J. Contribution of clinical breast examination to mammography screening in the early detection of breast cancer. J Med Screen. 2003;10:16-21.

14. Ezegwui HU, Onoh RC, Ikeako LC, et al. Investigating maternal mortality in a public teaching hospital, Abakaliki, Ebonyi State, Nigeria. Ann Med Health Sci Res. 2013;3(1):75-80.

15. Adetifa FA, Ojikutu, RK. Prevalence and trends in breast cancer in Lagos State, Nigeria. Afr Res Rev. 2009;3(5):1-15.

16. Daniel WW. Biostatistics: A Foundation for Analysis in the Health Sciences. 7th ed. New York, NY: John Wiley \& Sons; 1999.

17. Shahbaz T, Nisa K. Knowledge and practice of breast self-examination among antenatal clinic attendees presenting to a tertiary care hospital in Karachi, Pakistan. JUMDC. 2013;4(1):49-55.

18. Okobia MN, Bunker CH. Epidemiological risk factors for breast cancera review. Nig J Clin Pract. 2005;8(1):35-42.

19. Robbins J, Jeffries D, Roubidoux M, Helvie M. Accuracy of diagnostic mammography and breast ultrasound during pregnancy and lactation. AJR Am J Roentgenol. 2011;196(3):716-722. doi:10.2214/ AJR.09.3662.

20. Haghighi M. Comparative study of clinical breast examination and imaging results to find breast masses. Iran J Radiol. 2005;3(1):22.

21. Romero C,Lombardía J, Almenar A, et al. Diagnosis and treatment of benign breast lesions during pregnancy. Radiologia. 2007;49(4):255-261.

\section{Dovepress}

patient perspectives such as quality of life, adherence and satisfaction. The manuscript management system is completely online and includes a very quick and fair peer-review system, which is all easy to use. Visit http://www.dovepress.com/testimonials.php to read real quotes from published authors. 